\title{
Encefalitis rábica humana por mordedura de murciélago en un área urbana de Colombia
}

\author{
Reynaldo Badillo ${ }^{1}$, Julio César Mantilla², Gustavo Pradilla ${ }^{1,3}$ \\ 1 Departamento de Medicina Interna, Escuela de Medicina, Hospital Universitario de Santander, \\ Universidad Industrial de Santander, Bucaramanga, Colombia. \\ 2 Departamento de Patología, Escuela de Medicina, Universidad Industrial de Santander, Bucaramanga, \\ Colombia. \\ ${ }^{3}$ Unidad de Neurología, Escuela de Medicina, Hospital Universitario de Santander, Universidad Industrial \\ de Santander, Bucaramanga, Colombia.
}

Se presenta el caso de un adolescente con encefalitis rábica adquirida cuatro meses después de ser mordido por un murciélago en el área urbana de Floridablanca (Santander), Colombia.

La complejidad de sus manifestaciones clínicas hizo muy difícil confirmar el diagnóstico antes de su muerte, principalmente por su período de incubación y la ausencia de casos similares en áreas diferentes de las selváticas.

A pesar de las diversas estrategias terapéuticas, que incluyeron el denominado Protocolo de Milwaukee, el paciente falleció luego de 19 días de evolución y la necropsia confirmó que se trataba de una panencefalitis aguda necrosante de etiología viral rábica. La prueba de inmunofluorescencia directa en tejido cerebral fue positiva, lo mismo que la prueba biológica con ratones. La tipificación viral mostró la variante antigénica 3, cuyo reservorio principal es el vampiro hematófago Desmodus rotundus.

Con el reporte de este caso de encefalitis rábica por mordedura de un murciélago, probablemente el primero informado en un área urbana de Colombia y de los pocos en América Latina, alertamos a las autoridades sanitarias y a la comunidad en salud, para aumentar y fortalecer las medidas preventivas en todos los niveles.

Palabras clave: encefalitis, rabia, quirópteros, zoonosis, autopsia, Colombia.

\section{Human rabies encephalitis by a vampire bat bite in an urban area of Colombia}

A case of rabies encephalitis is presented in a teenaged male, which developed four months after a bat bite in the urban area of Floridablanca, Santander Province, Colombia. The complex clinical manifestations prevented the confirmation of an antemortem diagnosis, principally because of the lengthy incubation period and the absence of other similar urban cases. Despite application of several therapies, including the Milwaukee protocol, the patient died 19 days after hospital admission. The autopsy revealed a necrotic, acute, pan-encephalitis of rabies virus etiology. The test of direct immunofluorescence in brain tissue was positive, as well as the biologic test in mice. Serological tests indicated it to be an antigenic variant type 3, whose main reservoir is the hematophagous vampire bat, Desmodus rotundus. This is probably the first case of bat-induced rabies reported in an urban community of Colombia and one of the few in Latin America. Although rabies encephalitis by a bat bite is rare, the case serves as a notice to health authorities and to the medical community to be alert to this risk.

Key words: Encephalitis, rabies, chiroptera, zoonoses, autopsy, Colombia.

Correspondencia:

Gustavo Pradilla, Carrera 29 № 32-65, Edificio San Diego, apartamento 201, Bucaramanga, Colombia.

Teléfono: (57) 634 0292; fax: (57) 6551054

gustavop@uis.edu.co

Recibido: 21/08/08; aceptado:18/12/08
La rabia es una zoonosis viral que causa, aproximadamente, 50.000 casos nuevos anualmente en el mundo, o sea, casi uno cada 10 minutos. La mayoría de los casos ocurren en países en desarrollo y los perros son el principal vector en ellos (1). Sin embargo, existen otros 
vectores como los murciélagos, los felinos, los zorrillos y otros mamíferos con glándulas salivares funcionales (2).

El virus de la rabia es un virus ARN perteneciente al género Lyssavirus, usualmente transmitido a los humanos por la saliva infectada de un animal rabioso, mediante su mordedura.

Se han descrito otras formas de exposición sin mordedura, como los casos de contaminación de una herida abierta, arañazo, abrasión o laceración de una membrana mucosa, por saliva o tejido nervioso infectado. Se ha comprobado, además, la transmisión a humanos por inhalación del virus de la rabia presente en aerosoles suspendidos en el aire de cavernas en las que habitan gran cantidad de murciélagos, así como en accidentes de laboratorio y mediante el trasplante de córneas infectadas con el virus $(3,4)$.

Su período de incubación es variable y usualmente está en un rango de 30 a 90 días aunque, en ocasiones, ha sido de hasta un año (5). Sin embargo, este período puede llegar a ser tan corto como de siete días y tan largo como de seis años, o incluso más $(6,7)$.

La rabia se caracteriza clínicamente por una encefalitis progresiva y el tratamiento es paliativo, principalmente. La enfermedad es casi invariablemente fatal una vez se inician los síntomas neurológicos $(3,8)$.

No obstante, se ha informado la supervivencia en algunos casos aislados; todos estos pacientes fueron sintomáticos y recibieron profilaxis antes o después de la exposición, y en ninguno de ellos se demostró el virus de la rabia mediante exámenes de laboratorio (9).

La infección por virus rábicos ocurre en dos formas epidemiológicas diferentes: a) la rabia urbana, con el perro como principal reservorio transmisor a los humanos, y b) la rabia silvestre o selvática, transmitida por especies depredadoras, como las felinos, y animales, como el zorro, los murciélagos, el chacal y otros, que actúan como reservorios y transmisores, principalmente, a especies herbívoras (10).
En Colombia, la rabia humana casi siempre se ha asociado con su transmisión por la mordedura de perros, especialmente en las áreas urbanas $(2,11)$.

La rabia silvestre que ha revestido la mayor importancia en otros países, se ha presentado ocasionalmente en Colombia y ello amerita una mayor atención y un permanente manejo integral. Las mordeduras de zorros, murciélagos, primates y otros animales salvajes, aun los domesticados, deben considerarse como una exposición grave que requiere tratamiento inmediato $(10,12-14)$.

Por las características ecológicas y sociales de las áreas tropicales y subtropicales de las Américas, la rabia transmitida por murciélagos hematófagos (vampiros) adquiere una particular seriedad para la salud pública. En general, se ha encontrado que la frecuencia de agresiones de los vampiros al hombre se ve influenciada por ciertas intervenciones; las más comunes son el retiro de animales de una zona densamente poblada, el inicio de las actividades de desmonte y la exploración de minas (15).

Las especies de murciélagos hematófagos, o vampiros, son sólo tres y habitan exclusivamente en América Latina. Desmodus rotundus es el más ampliamente distribuido en la zona y se alimenta de sangre de vertebrados, aunque esporádicamente lo hace de aves. Las otras dos especies son Diaemus youngi (vampiro de alas blancas) y Dyphylla ecaudata (vampiro de patas peludas), las cuales son muy escasas y usualmente se alimentan de sangre de aves. Todos los reportes de brotes de rabia en humanos causadas por vampiros se han relacionado exclusivamente con $D$. rotundus (10).

La Organización Mundial de la Salud ha considerado que $89 \%$ de los casos de rabia en animales silvestres en América, proceden de Canadá y Estados Unidos. Sin embargo, es probable que esta incidencia obedezca a la poca atención y vigilancia en los países latinoamericanos (16).

Los brotes epidémicos son los responsables del mayor número de víctimas en América Latina 
y, en el 2004, la Oficina Panamericana de la Salud contabilizó 46 casos humanos de rabia transmitida por murciélagos hematófagos en Brasil, Colombia (14), Perú (8) y Venezuela $(2,17)$.

En México, en 1997, el 9\% de los casos humanos se debieron a agresiones por quirópteros, y en 1998 se incrementaron a 46,7\%. En 1998, hubo cuatro defunciones por encefalitis rábica por murciélago hematófago en la Sierra Tarahumara del estado de Chihuahua y, en 1999, en este mismo estado hubo otro caso (16).

En el 2006 se diagnosticó rabia por murciélago hematófago en una paciente de 12 años de una localidad rural de Yucatán con encefalitis viral, sin antecedentes o evidencia de agresión por algún animal. Su vivienda era precaria y colindaba con una cueva de quirópteros. Se confirmó el diagnóstico post mórtem de rabia, y se identificó la variante antigénica V5 de murciélago hematófago (18).

El mayor número de casos humanos de rabia que se notifican en el Perú son causados por D. rotundus. Desde 1975 hasta el 2003, se informaron en el Perú 250 decesos como consecuencia del ataque de murciélagos hematófagos, principalmente, de tipo silvestre y en el Amazonas $(19,20)$.

En Panamá, en el 2002, se publicó un caso de rabia en una mujer de 69 años de edad con paraplejia posterior a mordedura por un vampiro, cuya necropsia confirmó el diagnóstico, y fue el primer caso de rabia selvática informado en ese país. No se informó si se aisló alguna variante antigénica (21).

En el 2004 se presentaron dos brotes de rabia paralítica transmitida por murciélagos en dos áreas remotas de la selva amazónica brasileña. Hubo 21 muertos y todos ellos habían sido mordidos por murciélagos vampiros. Se aisló la variante antigénica 3 asociada a $D$. rotundus (22).

La presencia del vampiro $D$. rotundus en nuestro país es significativa, como lo demostró un estudio de campo en el departamento de Sucre, donde se encontró este quiróptero en la zona rural en el $100 \%$ de los muestreos y su total ausencia en la zona urbana (23).

Si bien es cierto que se ha enfatizado en la importancia de los murciélagos hematófagos, en especial, $D$. rotundus, en la transmisión de la rabia humana y primordialmente la silvestre, debe tenerse en cuenta que los quirópteros no hematófagos también pueden transmitirla.

La rabia transmitida por murciélagos no hematófagos es un problema que afecta en especial a poblaciones urbanas y a las áreas desarrolladas económicamente. El riesgo se debe a la transmisión directa del murciélago al hombre o del murciélago a otras especies domésticas que pueden actuar como transmisores incidentales. No obedece a patrones epidemiológicos definidos y en varios casos registrados la agresión ha pasado desapercibida por el paciente, y se llegó post mórtem al diagnóstico de rabia producida por el murciélago. En estos casos, la atención médica no es posible, lo que implica una dificultad particular adicional que destaca la importancia de la vigilancia (24).

Entre 1981 y 1997 ocurrieron 20 casos de rabia en humanos transmitida por murciélagos no hematófagos en los Estados Unidos, lo que indica claramente su importancia como reservorios de la enfermedad (25).

En varios países latinoamericanos se ha identificado el virus de la rabia en esta clase de quirópteros, como en México en poblaciones rurales y en ciudades capitales, en especímenes de los géneros Artibeus rda y Taradia brasiliensis, en este último con una variante antigénica 9 (AgV9) que es la misma identificada en Estados Unidos $(16,26)$. En Chile y en Argentina se ha informado también la presencia del murciélago no hematófago $T$. brasiliensis con rabia y con una variante antigénica diferente que es la 4 (26-28).

Ha habido también casos humanos de rabia transmitida por quirópteros no hematófagos en México, Chile y Argentina $(16,29,30)$.

En Colombia se ha encontrado rabia en murciélagos insectívoros de las especies Molossus molossus y Epttesicus braziliensis en 
los alrededores de Cali, en 1995 y en el 2000, reservorios que constituyen una amenaza para la salud pública en el país. Sin embargo, no hay informes publicados de casos humanos de rabia por estos quirópteros (31).

Los primeros casos en Colombia de rabia humana por murciélagos se informaron en la década de los 80 , cuando dos personas murieron de rabia transmitida por quirópteros en la región del Darién (12).

Posteriormente, en 1996, se presentaron tres casos nuevamente en Chocó y en el 2004 se reportó un brote de rabia en la comunidad indígena embera, localizada en las márgenes del río Purricha, en la zona norte del Bajo Baudó. Fallecieron 14 niños, entre 4 a 12 años, en dos de los cuales el laboratorio del Instituto Nacional de Salud confirmó rabia (12). En enero de 2005 hubo otro brote similar de menor magnitud, con tres víctimas adicionales en las comunidades negras de Pató y Nauca, municipio del Alto Baudó. De todos estos 17 casos, cuatro fueron confirmados positivos para rabia y los otros 13 se dedujeron por nexos epidemiológicos. Se aisló la variante antigénica 3 , típica de rabia transmitida por murciélago hematófago, como la única variante presente en el material encefálico de la necropsia $(10,12,13)$.

En este documento presentamos un caso de rabia humana transmitida por murciélago en el municipio de Floridablanca (Santander) que es, al parecer, el primero de esta naturaleza informado en Colombia y de los pocos casos documentados en América Latina, en una comunidad urbana.

\section{Presentación del caso}

Se trata de un paciente de 15 años de edad, de sexo masculino, natural de Piedecuesta y procedente del área urbana de Floridablanca, estudiante de secundaria, que consultó el 10 de abril de 2008 a una clínica en Bucaramanga por dificultad para comer, astenia, adinamia, cefalea y fiebre de tres días de evolución. No refería antecedentes de importancia.

En su examen general se encontró álgido, asténico, afebril al tacto, con signos vitales normales, amígdalas eritematosas y con placas blanquecinas, y adenopatías cervicales. Su examen neurológico fue normal. Con el diagnóstico de amigdalitis se prescribió tratamiento ambulatorio con penicilina benzatínica, diclofenaco y amoxicilina.

Tres días después consultó nuevamente por persistencia de la fiebre, náuseas, odinofagia y osteomialgias. En el examen se encontraba febril $\left(39^{\circ} \mathrm{C}\right)$, con tensión arterial de 119/70 mm $\mathrm{Hg}$, frecuencia cardíaca de 100 latidos por minuto y frecuencia respiratoria de 16 por minuto. Su faringe estaba granulosa, tenía dolor en el marco cólico y el resto de su examen, incluido el neurológico, era normal.

Con la impresión diagnóstica de dengue o de faringitis viral, se practicó un cuadro hemático: leucocitos, $11.400 \times \mathrm{mm}^{3}$ (neutrófilos, $80 \%$ ); hemoglobina, $17 \mathrm{~g} / \mathrm{dl}$, y plaquetas de 319.000 $x \mathrm{~mm}^{3}$. Se obtuvo, también, radiografía del tórax, antígenos febriles y parcial de orina, que fueron normales. Se medicó con dipirona y dexametasona.

Tres horas y media después presentó intolerancia a los líquidos por espasmo faríngeo, el cual recurrió cuatro horas más tarde. Se encontraba alerta y con eritema faríngeo. El examen de los electrolitos séricos mostró sodio de $129 \mathrm{mmol} / \mathrm{L}$. Con la impresión diagnóstica de síndrome febril e hiponatremia, se formuló dipirona.

Al día siguiente se encontraba alerta, febril $\left(39^{\circ} \mathrm{C}\right)$, con osteomialgias y debilidad muscular difusa, sin signos de irritación meníngea y con auscultación pulmonar normal. Por la sospecha de neumonía o de encefalitis fue evaluado por un médico internista en el servicio de urgencias, quien documentó que había presentado inicialmente dolor en el hombro derecho, que la fiebre era continua y que presentaba disartria, desorientación episódica, dificultad para la marcha, vértigo, cefalea y vómito. La madre del paciente refirió en ese momento el antecedente de mordedura por murciélago en la mano derecha cuatro meses antes. Se encontró el paciente en regular estado, somnoliento, orientado pero con incoherencias verbales, disminución de la fuerza en miembros inferiores y ausencia de signos de 
irritación meníngea. Con la impresión clínica de posible encefalitis viral o por rabia, se solicitó tomografía computadorizada (TC) del cráneo y valoración por un médico neurólogo.

Doce horas después presentó agitación, desorientación, disfagia y paresia de miembros inferiores, por lo cual fue sedado con diazepam. Fue referido a una institución de tercer nivel, donde ingresó ocho horas después, en el octavo día de evolución de su afección, Allí decidieron estudiar la posibilidad de encefalitis $y$, por el antecedente de mordedura de murciélago, descartar rabia, a pesar del antecedente tardío. Se informó al Instituto Nacional de Salud que ordenó remitir una muestra de suero refrigerado para estudiar virus de la rabia. Sin embargo, se consideró poco probable que el caso correspondiera a rabia dado el antecedente de la zona epidemiológica de la exposición (zona urbana de Floridablanca) y el tiempo transcurrido desde la mordedura por el murciélago.

El día de su ingreso se practicó la TC de cráneo, que mostró ventrículos cerebrales disminuidos de tamaño y sin zonas de hipercaptación. En la punciónlumbarseencontrópresióndeaperturade $24 \mathrm{~cm}$ de agua. El examen citoquímico del líquido cefalorraquídeo fue normal; las coloraciones de Gram, KOH, BK y tinta china, y los antígenos bacterianos fueron negativos. Su cuadro hemático reveló leucocitosis (23.420 glóbulos blancos $\times \mathrm{mm}^{3}$ con $87 \%$ de segmentados), proteína $C$ reactiva de $0,3 \mathrm{mg} / \mathrm{L}$ (normal, 0,08 a $3,10 \mathrm{mg} / \mathrm{L}$ ) .Su temperatura era de $39^{\circ} \mathrm{C}$, la tensión arterial de $107 / 99 \mathrm{~mm} \mathrm{Hg}$ y la frecuencia cardiaca de 114 latidos por minuto. Presentaba agitación psicomotora, episodios de acentuada somnolencia y pupilas isocóricas de $3 \mathrm{~mm}$ de diámetro y reactivas a la luz. Se formuló manitol por la hipertensión endocraneana y aciclovir por su cuadro clínico sugestivo de encefalitis viral, además de dipirona. Se le practicó intubación orotraqueal y se le dio asistencia respiratoria mecánica. Sin embargo, persistía febril $\left(39,5^{\circ} \mathrm{C}\right)$ y con hipertensión arterial (167/98 mm Hg). Recibió sedación con fentanilo y relajación con vecuronio. Se encontró, también, hiponatremia e hipopotasemia. Por su hipertensión arterial se medicó con nitroprusiato sódico.
En el día noveno de su evolución, continuó febril $\left(38^{\circ} \mathrm{C}\right)$, taquicárdico (164 latidos por minuto) e hipertenso $(162 / 108 \mathrm{~mm} \mathrm{Hg})$. Fue evaluado por el Servicio de Neurología que consideró que el antecedente de mordedura de murciélago hacía poco probable la etiología rábica. En ese momento presentó una crisis convulsiva tónico-clónica generalizada, que fue controlada con midazolam y se prescribió fenitoína. Se consideró que el cuadro era muy sugestivo de encefalitis viral, probablemente herpetiforme, y se recomendó administrar dexametasona a dosis de $24 \mathrm{mg}$ al día, además del tratamiento instaurado previamente.

En el día 12 de evolución, continuaba con deterioro neurológico (Glasgow de 4/15), patrón respiratorio irregular, con medidas generales para el edema, terapia antiviral y cobertura con antibióticos de primera línea por sospecha de coinfección pulmonar. Se practicó una resonancia magnética cerebral con gadolinio que fue normal. Al interrogarse nuevamente a la madre, refirió que el cuadro clínico se había iniciado con debilidad del miembro superior derecho y fiebre, asociados a síntomas de amigdalitis; posteriormente, disfagia para líquidos, mareos y debilidad para sostenerse de pie y para caminar. Se suspendieron los sedantes y el paciente presentó coma profundo, seguía febril, con pupilas puntiformes y ausencia de reflejos del tallo encefálico.

En el día 15 de su enfermedad tuvo varios episodios convulsivos tónico-clónicos generalizados y continuó en un estado comatoso profundo. Por el bajo nivel de colinesterasa sérica, el Servicio de Neurología conceptuó que presentaba un bloqueo, insistió en la probabilidad tóxica y recomendó medir niveles de plaguicidas.

Al día siguiente, el paciente se encontraba dependiente de medicamentos vasoactivos por choque vasopléxico y también del respirador mecánico, y con suplencia de vasopresina por diabetes insípida; un examen de Doppler transcraneal fue negativo para muerte cerebral.

Diecisiete días después de iniciarse su afección y en vista de su evolución, el Servicio de Neurología consideró que el paciente presentaba 
una lesión difusa grave del sistema nervioso central de causa no establecida y solicitó el perfil inmunológico por un posible proceso autoinmune catastrófico. Sin embargo, en la junta médica se estableció que podría tratarse de un caso infrecuente de rabia humana y decidieron iniciar inducción de coma con ketamina, midazolam, pentotal sódico, ribavirina y amantadina.

En el día 18 de evolución, un nuevo examen de Doppler transcraneal reveló ausencia de flujo, compatible con muerte cerebral. Ese mismo día, el Instituto Nacional de Salud confirmó telefónicamente que la muestra enviada era negativa para encefalitis equina y que no recibieron el material biológico enviado para estudiar rabia.

El 26 de abril de 2008 se practicó una nueva TC cerebral que mostró edema grave con reforzamiento meníngeo. Se retiraron las medidas de soporte, el paciente presentó paro cardiorrespiratorio y las maniobras de reanimación fueron infructuosas. Falleció después de 19 días de haberse iniciado su cuadro clínico. Ese mismo día se practicó la necropsia en el Departamento de Patología de la Escuela de Medicina de la Universidad Industrial de Santander.

\section{Estudio de autopsia}

En el examen interno se encontró un encéfalo edematoso, congestivo, muy reblandecido, de $1.300 \mathrm{~g}$ de peso, con giros y circunvoluciones aplanadas y obliteración de los surcos y cisuras, con pequeños focos de hemorragia subaracnoidea (figura 1). Al corte transversal y a nivel de ganglios basales, se apreció colapso del sistema ventricular, necrosis generalizada de la corteza cerebral, hemorragias puntiformes en la sustancia blanca y distorsión extrema del tallo cerebral y del cerebelo (figura 2). Se tomaron muestras de los lóbulos frontales, los temporales, el mesencéfalo y el segmento C1 de la médula espinal, las cuales se remitieron al Instituto Nacional de Salud para hacer estudios confirmatorios de rabia.

Elexamenmicroscópicodeltejidonerviosomostró congestión, edema e infiltrados de linfocitos

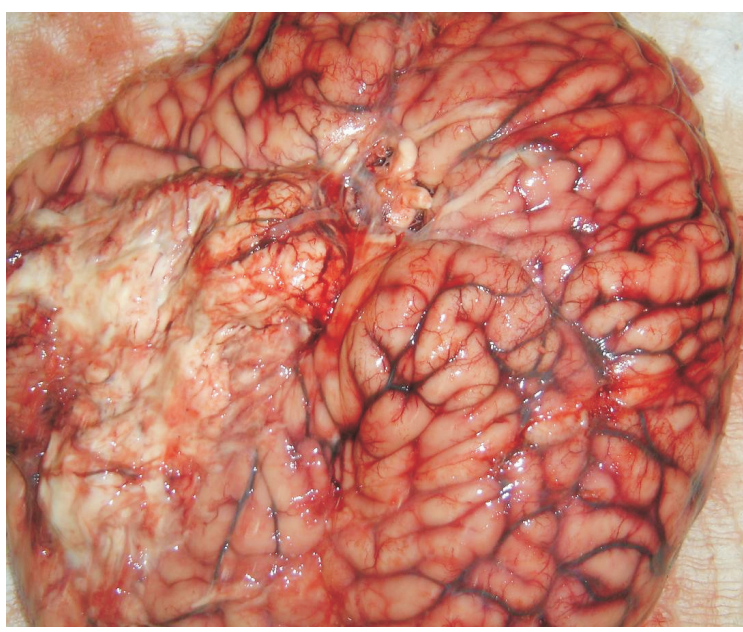

Figura 1. Imagen en fresco del encéfalo del paciente, donde se aprecia edema, congestión, focos de hemorragia subaracnoidea y necrosis por licuefacción de la mayor parte del tallo cerebral y del cerebelo.

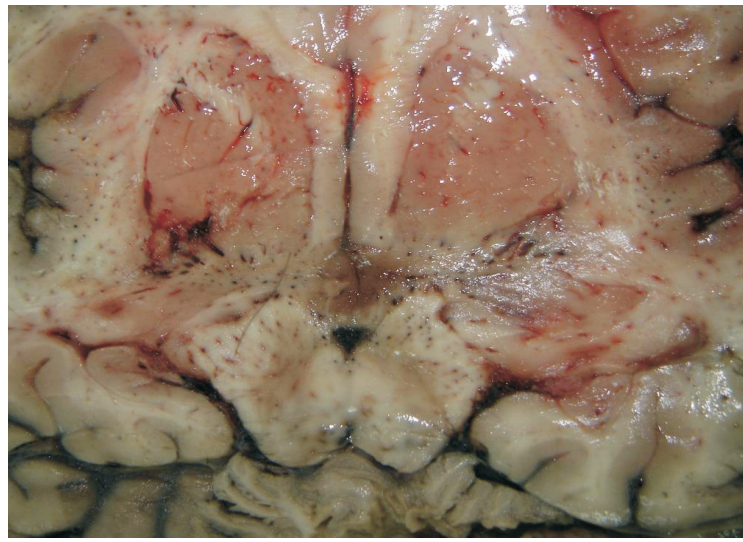

Figura 2. Imagen del corte del encéfalo del paciente tras una semana de fijación con formaldehído al 10\%, en la cual se reconoce colapso del sistema ventricular, hemorragias puntiformes en los ganglios basales y necrosis multifocal por licuefacción.

alrededor de los pequeños vasos sanguíneos, a manera de manguitos perivasculares (figura 3). La casi totalidad de las neuronas presentaba pérdida de su núcleo y se encontraban transformadas en masas eosinófilas rodeadas por linfocitos, macrófagos y células gliales. Se identificaron inclusiones en el citoplasma de muy escasas neuronas, las cuales correspondieron a cuerpos de Negri (figura 4). Los anteriores hallazgos permitieron establecer el diagnóstico de panencefalitis aguda necrosante de posible etiología viral rábica. 
El Grupo de Patología del Instituto Nacional de Salud estudió las muestras enviadas y confirmó el diagnóstico de panencefalitis aguda grave necrosante, indicativa de etiología viral.

El Grupo de Virología del Instituto Nacional de Salud practicó un estudio de inmunofluorescencia directa, el cual fue positivo para rabia, con presencia ubicua de corpúsculos de Negri de tamaño reducido y polvillo antigénico rábico en cerebelo, asta de Amón derecha e izquierda, lóbulos temporales y mesencéfalo, y mayor presencia de antígeno rábico en los lóbulos

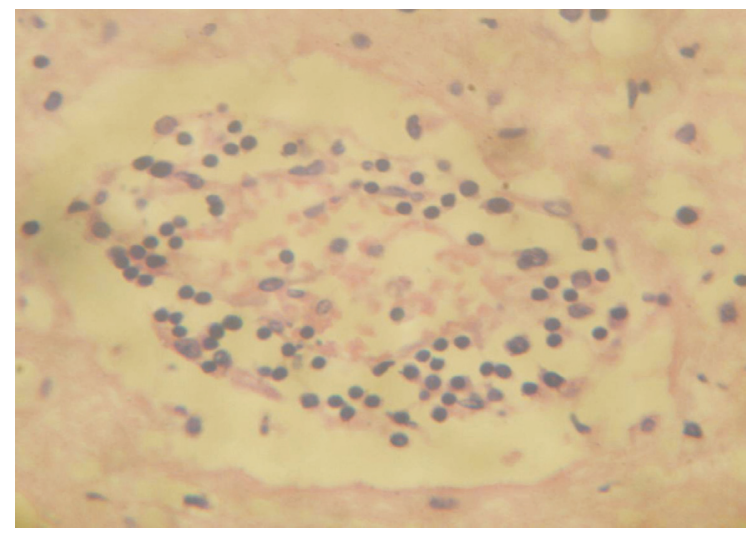

Figura 3. Imagen microscópica del lóbulo frontal del cerebro del paciente, en la cual se reconocen amplios espacios de Virchow Robin, e infiltrado mononuclear linfocitario dispuesto a manera de manguitos perivasculares. Hematoxilinaeosina, 10X.

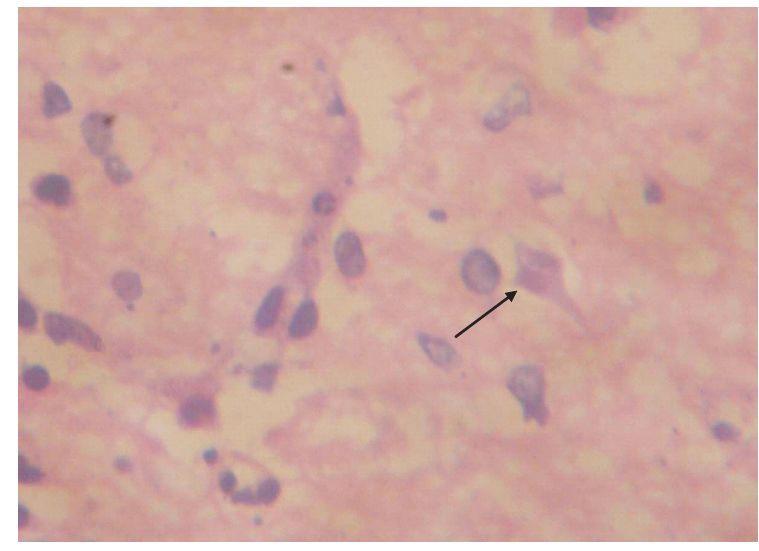

Figura 4. Imagen microscópica del cerebro del paciente en la cual se identifica una neurona piramidal con una inclusión intracitoplásmica eosinófila (cuerpo de Negri), localizada hacia la periferia e indicada con la flecha. Alrededor hay macrófagos y células gliales. Hematoxilina-eosina, 40X. temporales. Se realizó también una prueba biológica con inoculación de tejido nervioso del paciente a ratones de la cepa IRA, con resultado positivo.

La tipificación viral mostró la variante antigénica 3 , cuyo reservorio principal es el vampiro hematófago $D$. rotundus.

\section{Discusión}

Este caso de rabia humana por mordedura de murciélago, confirmado por anatomía patológica y pruebas específicas de laboratorio, es el primero informado, de acuerdo con nuestro conocimiento, en un paciente residente en una zona urbana de Colombia y uno de los pocos no selváticos en América Latina.

La mordedura por el murciélago se presentó en un campo de baloncesto alrededor de las 6 p.m. en el municipio de Floridablanca, población adscrita al área metropolitana de Bucaramanga y que cuenta con alrededor de 250.000 habitantes, lo que la convierte en la segunda ciudad del departamento de Santander. Al caer al piso varios murciélagos, el paciente cogió con su mano a uno de ellos y fue mordido en una de sus manos. No fue por agresión espontánea del quiróptero, ni en un lugar rural apartado, ni mucho menos selvático.

Los 22 casos documentados de rabia humana por murciélagos en Colombia han sido de tipo silvestre y en el departamento del Chocó $(10,12,13)$. Hasta ahora no se tenía evidencia de ningún caso comprobado en pacientes de zonas urbanas de nuestro país.

El paciente fue mordido por un murciélago que no fue atrapado y, por ende, no se pudo clasificar, pero la variante antigénica hallada en el material de necropsia fue la 3, cuyo reservorio principal es el quiróptero hematófago $D$. rotundus, similar a los casos de brotes de rabia humana transmitida por vampiros en el Chocó (10). Por ello asumimos que se trata de un caso de rabia humana transmitida por vampiro.

Los estudios de campo en nuestro país han señalado la frecuencia del murciélago hematófago $D$. rotundus (23) y Santander ha sido 
considerado por el Instituto Colombiano Agropecuario como zona de alto riesgo, en relación con la rabia de origen silvestre (32), aspectos que consideramos favorecieron la presentación de este caso y que nos deben alertar sobre otros posibles.

Aunque se han descrito murciélagos no hematófagos con rabia en nuestro país, los estudios de tipificación viral señalan variantes antigénicas diferentes de la 3 , como fue la de nuestro paciente $(26,27,29,31)$.

A finales del 2007 se informó en Ubatuba, estado de São Paulo, Brasil, de un murciélago vampiro (D. rotundus) atrapado en dicha localidad urbana infectado con rabia, diagnosticado en el Instituto Pasteur de ese país. Los autores alertaron a la comunidad sobre el serio problema de salud pública que este hallazgo representaba (33). Sin embargo, los casos brasileños de rabia humana por $D$. rotundus se han descrito en pobladores de la jungla amazónica $(15,17,22)$.

En América Latina se han publicado casos de rabia humana transmitida por murciélago hematófago en localidades diferentes de las selváticas, pero usualmente en comunidades rurales, como en la Sierra Tarahumara del estado de Chihuahua en México y en Tekax en el estado de Yucatán con viviendas precarias y a veces colindando con cuevas de quirópteros $(16,18)$. Este último caso fue bien estudiado, y se identificó la variante antigénica 5 de murciélago hematófago (18).

La sintomatología clínica de la rabia es compleja y comúnmente causa confusión a los médicos $(5,6)$, como en este caso, cuyo diagnóstico no fue sospechado inicialmente a pesar de conocerse de la mordedura del murciélago, porque en nuestro país la rabia se ha asociado siempre a la mordedura por perros, por provenir el paciente de un área no silvestre y por su período de incubación de cuatro meses que minimizó su importancia inicialmente para los familiares.

Las características clínicas de la rabia se dividen en cinco estadios: el período de incubación, los pródromos, la fase neurológica aguda, el coma y la muerte.
Debido a su diversidad clínica durante la fase neurológica aguda, la rabia puede distinguirse como clásica (formas encefalítica o furiosa y paralítica o muda) y no clásica. La forma clásica se asocia casi siempre con el virus de la rabia verdadera (genotipo 1). Las formas no clásicas se encuentran en pacientes expuestos a los murciélagos, aunque se ha visto también en pacientes tailandeses infectados por perros (6,34-36).

Los períodos de incubación más largos se han asociado a la infección por murciélagos $(6,7)$. El estado prodrómico se caracteriza, en las tres cuartas partes de los pacientes infectados por murciélagos, por síntomas locales como dolor neuropático porque el virus se mueve centrípetamente de la periferia al ganglio de la raíz dorsal (6).

La rabia transmitida por murciélagos presenta características clínicas diferentes a la relacionada con los perros (formas encefalítica y paralítica), con dolor neuropático, déficit motor, movimientos coreiformes, signos focales del tallo cerebral, mioclono, ataxia, vértigo, crisis convulsivas y alucinaciones. La mitad de los casos presentan espasmos fóbicos $(3,6,34,36)$.

En la fase aguda hay tres signos cardinales: fluctuaciones de la conciencia, espasmos fóbicos o inspiratorios y signos de estimulación autonómica; además, alteraciones mentales, agitación y depresión que es seguida por deterioro de la conciencia y coma (6). La fiebre es una constante y hay una taquicardia desproporcionada a ella.

El coma precede a la insuficiencia circulatoria que es la primera causa de muerte $(6,34)$.

Nuestro paciente presentó un cuadro de encefalitis grave iniciado por dolor en el miembro superior cuya mano fue mordida por el murciélago, seguido de fiebre que fue una constante durante toda la enfermedad, con espasmosfóbicosiniciales, déficit motor, vértigo, crisis convulsivas, disautonomía con hipertensión arterial y taquicardia, agitación psicomotora, deterioro progresivo del estado de conciencia e insuficiencia circulatoria que lo llevó a la muerte. 
Su período de incubación fue de cuatro meses, lo que confundió inicialmente a sus familiares que no le dieron la importancia que merecía y, posteriormente, a sus médicos, en especial a los neurólogos.

También el hecho de que $99 \%$ de los casos de rabia reportados mundialmente, se deben a mordeduras por perros y son escasos los causados por otras especies, en especial los murciélagos (37).

Sin embargo, el médico internista que lo evaluó inicialmente tuvo una sospecha racional de encefalitis viral y, en especial, rábica.

Los exámenes de laboratorio de rutina no son diagnósticos. El cuadro hemático usualmente es normal, pero puede presentar una discreta leucocitosis con neutrofilia. Se ha encontrado hiponatremia en una tercera parte de los casos, por ingestión inadecuada de sodio o por el síndrome de secreción inapropiada de hormona antidiurética. El líquido cefalorraquídeo revela una presión normal o un poco elevada; el número de células usualmente es normal, pero en una tercera parte de los casos hay pleocitosis moderada con predominio de linfocitos; las proteínas pueden estar un poco elevadas (menos de $100 \mathrm{mg} \%$ ) y la glucorraquia es normal $(6,38)$.

En el caso presentado inicialmente hubo una discreta leucocitosis que se incrementó luego por infecciones adicionales; la hiponatremia se documentó en dos ocasiones y el líquido cefalorraquídeo fue normal en la única punción lumbar realizada en el octavo día de su evolución, aunque su presión estaba elevada por la hipertensión endocraneana.

Son muy escasos los informes neurorradiológicos en casos de rabia humana. La TC del cráneo puede mostrar áreas focales o difusas de atenuación en los ganglios basales, la sustancia blanca periventricular, el hipocampo y el tallo cerebral, e incluso, hemorragias del puente $(39,40)$. La resonancia magnética puede ser normal o señalar en la secuencia de T2 imágenes muy intensas en el tallo cerebral, hipocampo, hipotálamo, sustancia blanca sub- cortical y profunda, y sustancia gris cortical y profunda, con diversos grados de intensidad, según el estado de la enfermedad. El realce con el gadolinio se ve claramente sólo en los estadios finales $(5,6,39,40)$.

En el caso presentado aquí, las dos tomografías del cráneo sólo evidenciaron hipertensión endocraneana y la resonancia magnética realizada seis días antes de su fallecimiento, fue normal.

Su manejo terapéutico, al no sospecharse la rabia, incluyó el empleo de esteroides que están contraindicados por la inmunosupresión, factor éste que pudo favorecer la gravedad del cuadro clínico, como se observó en la necropsia.

Dos días antes de morir el paciente, el equipo médico tratante consideró el diagnóstico de rabia y decidió inducir coma con ketamina, midazolam, pentotal sódico, ribavirina y amantadina. Sin embargo, el paciente ya estaba en coma profundo cinco días antes y no hubo respuesta terapéutica alguna. En 2005, Willoughby et al. publicaron un caso de supervivencia después del tratamiento de una paciente con rabia con inducción del coma (41).

La hipótesis de este tratamiento, conocido ahora como el Protocolo de Milwaukee, se ha basado en que el estudio anatomopatológico del cerebro humano en los casos de rabia refleja complicaciones secundarias más que algún proceso primario definido y que un sistema inmune normal limpiaría, por así decirlo, el cerebro del virus. Los reportes clínicos han considerado la hipótesis de que la muerte resulta por el desequilibrio de los neurotransmisores y la falla autonómica, prediciéndose que el cuidado de soporte pudiera ser exitoso (41).

Para Jackson, es la disfunción neuronal más que la muerte neuronal el proceso cardinal en la rabia dado que, a pesar de los signos neurológicos graves y el desenlace fatal, hay cambios neuropatológicos relativamente modestos (42).

Por otra parte, la ketamina es un antagonista del receptor de $\mathrm{N}$-metil-D-aspartato con actividad específica contra la rabia en los modelos animales (43). Por todo lo anterior, se diseñó 
este protocolo como una estrategia para tratar de proteger el cerebro de la lesión, mientras se le permitía al sistema inmune desarrollar una respuesta natural y acabar con el virus. El cóctel terapéutico también incluía agonistas de receptores del ácido gamma-amino-butírico con benzodiazepinas y barbitúricos, además de amantadina para reducir la toxicidad por la excitación, el metabolismo cerebral y la reactividad autonómica. Además del coma inducido y la terapia antiviral, se incluía un soporte de cuidado intensivo $(41,42,44)$.

Sin embargo, el Protocolo de Milwaukee se ha empleado en seis casos más en diferentes países del mundo, cuatro de los cuales no recibieron profilaxis después de la exposición; todos los pacientes murieron y en la necropsia se comprobó la presencia del virus, a pesar de haberse detectado anticuerpos específicos contra el virus rábico y comprobarse ausencia de virus en los fluidos corporales (9).

Lamentablemente, el manejo de la rabia clínica en pacientes no vacunados es principalmente paliativo y la muerte es invariablemente su desenlace.

Desde el punto de vista de la neuropatología, el cuadro morfológico es indistinguible de cualquier otra encefalitis y se expresa por congestión, edema y ocasionales focos de hemorragia subaracnoidea. Microscópicamente los cambios son igualmente inespecíficos, representados en esencia por infiltración linfoide a manera de manguitos alrededor de los pequeños vasos del encéfalo y de la leptomeninge, además de infiltrado inflamatorio que se observa también en los ganglios nerviosos de las raíces posteriores y en los nervios periféricos. En las astas posteriores de la médula cervical, en la sustancia negra del mesencéfalo, el hipotálamo, los hemisferios cerebrales y el cerebelo, es frecuente observar nódulos inflamatorios, nódulos gliales 0 nódulos de Babes compuestos por agregados de linfocitos, microglía (macrófagos del tejido nervioso) y muy ocasionales astrocitos, además de neuronofagia; en algunos casos de curso prolongado y por razones desconocidas, la lesión inflamatoria es muy escasa o casi nula y la neuronofagia sólo se aprecia en algunas zonas aisladas.

La alteración morfológica considerada como distintiva de la rabia es la inclusión citoplasmática de forma ovoide o redondeada de tonalidad eosinófila con gránulos basófilos en su periferia, descrita por Negri y Bosc en 1903, la cual posteriormente fue denominada como cuerpo de Negri en honor a uno de sus descubridores. Esta inclusión se puede observar en las grandes neuronas de la formación del hipocampo, de los núcleos del mesencéfalo y en las células de Purkinje del cerebelo. En las áreas donde se identifican cuerpos de Negri, el infiltrado inflamatorio es escaso y no hay cambios en el neuropilo ni en la sustancia blanca (45). Es importante tener en cuenta que la presencia de los cuerpos de Negri no es un hallazgo constante, sólo se identifican en $20 \%$ a $50 \%$ de los casos de rabia y, cuando se observan, están presentes en una de cada 150 neuronas examinadas; esto hace necesario el empleo de técnicas diagnósticas de inmunofluorescencia, microscopía electrónica, inmunohistoquímica, inoculación en ratones y hasta reacción en cadena de la polimerasa, mucho más sensibles y específicas (46).

Analizando las circunstancias iniciales en nuestro caso, el paciente fue mordido por un murciélago que escapó, lo que se considera como una lesión por agresión animal y que, por tratarse de uno salvaje, se califica como una exposición grave que requiere tratamiento inmediato por la alta probabilidad de transmisión del virus rábico. El tratamiento es específico con suero y vacuna antirrábicos, además de la adecuada y oportuna atención de la herida. La administración de corticoides está contraindicada. En Colombia se dispone de una inmunoglobulina antirrábica heteróloga (suero antirrábico de origen equino) y de una inmunoglobulina homóloga (de origen humano). Una vez se aplique cualquiera de las dos, se procede en forma inmediata a colocar la vacuna, siguiendo el esquema para después de la exposición siempre y cuando no se haya recibido anteriormente ningún tratamiento antirrábico. Se emplea la vacuna antirrábica humana en cultivos celulares en cinco dosis, los 
días $0,3,7,14$ y 30, por vía intramuscular en la región deltoidea.

La inmunoglobulina, o suero antirrábico, se aplica una vez en la vida a la misma persona (14).

Ninguna de estas conductas fue asumida en el tratamiento inicial y posterior en el caso presentado luego de la mordedura por el murciélago, lo cual refleja la ignorancia existente sobre esta enfermedad en los diversos niveles de atención involucrados.

En nuestra universidad conformamos un grupo interdisciplinario integrado por médico internista, infectólogo, neurólogo, patólogo y veterinario, y dimos varias conferencias en diversas instituciones asistenciales y educativas de Bucaramanga ilustrando y alertando sobre la rabia, en especial la asociada a la transmisión por murciélagos.

Es importante señalar que el tratamiento previo a la exposición está indicado como una estrategia preventiva, únicamente para aquellas personas que corren riesgo elevado y repetido de infección en virtud de su ocupación; consiste en administrar tres dosis de vacuna antirrábica en cultivos celulares los días 0,7 y 28 , previa verificación de los niveles de anticuerpos (14).

Este caso nos enseña que la rabia transmitida por murciélagos hematófagos, confinada previamente en regiones selváticas, ya se encuentra plenamente documentada en un área urbana de Colombia y debe alertar a las autoridades sanitarias y a la comunidad de atención en salud en general, para su prevención y atención oportunas.

La complejidad del cuadro clínico de la rabia humana debe motivar a su estudio, sin demeritar aspectos fundamentales como su período de incubación, que puede ser variable y más prolongado de lo pensado en la transmitida por murciélagos.

De los casos de rabia humana notificados oficialmente en Colombia en lo transcurrido del año 2008, ninguno ha sido por transmisión canina y todos ellos correspondieron a niños y adolescentes de áreas urbanas: dos en el Cauca por transmisión felina y uno en Santander por murciélago, lo que puede indicar un programa de vacunación exitosa en los perros pero no en los gatos (47).

Por ello, debe ampliarse el espectro de los potenciales vectores en los programas de prevención y educar a la comunidad sobre la terrible amenaza de adquirir la rabia por murciélagos, aun en áreas urbanas, como lo fue en nuestra experiencia.

\section{Conflicto de intereses}

Los autores declaramos que no existe ningún tipo de interés que pueda influir en los resultados de este artículo.

\section{Financiación}

No recibimos ninguna financiación diferente de nuestro salario como docentes de la Escuela de Medicina de la Universidad Industrial de Santander.

\section{Referencias}

1. Leung AK, Davies HD, Hon KL. Rabies: Epidemiology, pathogenesis, and prophylaxis. Adv Ther. 2007;24:1340-7.

2. Rodríguez LF. Situación de rabia canina y rabia paresiante en Colombia. Universidad Antonio Nariño. Fecha de consulta: 9 de noviembre de 2008. Disponible en: www.uan.edu.co/deans/veterinaria/publicaciones/ docs/articulos/situacion_rabia.pdf.

3. Jackson AC. Rabies. Can J Neurol Sci. 2000;27:278-83

4. Srinivasan A, Burton EC, Kuehnert MJ, Rupprecht C, Sutker WL, Ksiazek TG, et al. Transmission of rabies virus from an organ donor to four transplant recipients. N Engl J Med. 2005;352:1103-11.

5. Jackson AC. Update on rabies. Curr Op Neurol. 2002;15:327-31.

6. Hemachudha T, Laothamatas J, Rupprecht C. Human rabies: a disease of complex neuropathogenetic mechanisms and diagnostic challenges. Lancet Neurol. 2002;1:101-9.

7. Smith JS, Fishbein DB, Rupprecht CE, Clarck K. Unexplained rabies in three immigrants in the United States. A virologic investigation. N Engl J Med. 1991;324:205-11.

8. Takayama N. Rabies: a preventable but incurable disease. J Infect Chemother. 2008;14:8-14.

9. McDermid RC, Saxinger L, Lee B, Johnstone J, Gibney RT, Jhonson M, et al. Human rabies encephalitis 
following bat exposure: failure of therapeutic coma. CMAJ. 2008;178:557-61.

10. Valderrama J, García I, Figueroa G, Rico E, Sanabria J, Rocha N, et al. Brotes de rabia humana transmitida por vampiros en los municipios de Bajo y Alto Baudó, departamento del Chocó, Colombia 2004-2005. Biomédica. 2006;26:387-96.

11. Alvis $\mathbf{N}$. De la rabia humana de origen canino y otras vergüenzas. Rev MVZ Córdoba. 2006;11:779-80.

12. Escobar E. La rabia: crónica de una experiencia. Medicina. 2005;27:249-55.

13. Escobar E. La rabia transmitida por vampiros. Biomédica. 2004;24:231-6.

14. Instituto Nacional de Salud. Rabia. Guía práctica para la atención de personas agredidas por un animal potencialmente transmisor de rabia. Serie de notas e informes técnicos No. 4. Sexta Edición. Bogotá: Instituto Nacional de Salud; 2002.

15. Schneider MC, Santos-Burgoa C, Aron J, Muñoz B, Ruiz-Velasco S, Uieda W. Potential force of infection of human rabies transmitted by vampire bats in the Amazonian region of Brazil. Am J Trop Med Hyg. 1996;55:680-4.

16. Sireno MA, Cantú PC. Presencia del virus rábico en fauna silvestre en la jurisdicción sanitaria No. II del estado de San Luís Potosí (México). Revista Salud Pública y Nutrición. 2001;2. Fecha de consulta: 17 de noviembre de 2008. Disponible en: http://www.respyn. uanl.mx/ii/2/articulos/rabia-fs.html.

17. Schneider MV, Belotto A, Adé MP, Leanes LF, Correa $\mathbf{E}$, Tamayo $\mathbf{H}$, et al. Situación epidemiológica de la rabia humana en América Latina en 2004. Boletín Epidemiológico. 2005;26:2-4.

18. Briones S, Marín-Pech E. Estudio de caso de rabia humana transmitida por murciélago hematófago en Yucatán, México. Rev Biomed. 2006;17:118-22.

19. Navarro AM, Bustamante J, Sato A. Situación actual y control de la rabia en el Perú. Rev Perú Med Exp Salud Pública. 2007;24:46-50.

20. López A, Mirana P, Tejada E, Fishbein DB. Outbreak of human rabies in the Peruvian jungle. Lancet. 1992;339:408-11.

21. Castillo B, Mike E, De Bernard C. Caso clínico patológico. Rabia selvática en humanos por mordedura de vampiro: primer caso en humanos. Fecha de consulta: 17 de noviembre de 2008. Disponible en: http://www. telmeds.net/modules.php?name $=$ News\&file $=$ article $\&$ sid $=447$.

22. da Rosa ES, Kotait I, Barbosa FS, Carrieri ML, Brandao PE, Pinheiro AS, et al. Bat-transmitted human rabies out-breaks, Brazilian Amazon. Emerg Infect Dis. 2006;12:1197-202.
23. Sampedro AC, Martínez CM, De la Ossa K, Otero YL, Santos LM, Osorio S, et al. Nuevos registros de especies de murciélagos para el departamento de Sucre y algunos datos sobre su ecología en esta región colombiana. Caldasia. 2007;29:355-62.

24. Centro Panamericano de Fiebre Aftosa. América contra la rabia. Plan de acción para la prevención y el control de la rabia en las Américas: etapa 2005-2009. Río de Janeiro: PANAFTOSA, OPS, OMS; 2007. p. 4.

25. Noah DL, Drenzek CL, Smith JS, Krebs JW, Orciaria L, Shaddock J, et al. Epidemiology of human rabies in the United States, 1098 to 1996. Ann Int Med. 1998;128:92230 .

26. Loza-Rubio E, de Mattos CC, Aguilar A, de Mattos CA. Aislamiento y caracterización molecular de un virus rábico, obtenido de un murciélago no hematófago en la ciudad de México. Vet Mex. 2000;31:147-51.

27. Favic M, Yung V, Pavletic C, Ramírez E, de Mattos C, de Mattos CA. Rol de los murciélagos insectívoros en la transmisión de la rabia en Chile. Arch Med Vet. 1999;31:157-65.

28. de Mattos CA, Favi M, Yung V, Pavletic C, de Mattos CC. Bat rabies in urban centers in Chile. J Wildl Dis. 2000;36:231-40.

29. Favi M, de Mattos CA, Yung V, Chala E, López LR, de Mattos CC. First case of human rabies in Chile caused by an insectivorous bat virus variant. Emerg Infect Dis. 2002;8:79-81.

30. Amasino CF, Garbi CJ, Amasino MF. La rabia urbana en la provincia de Buenos Aires, Argentina: origen-evolución-actualidad. Analecta Veterinaria. 2002;22:17-31.

31. Paéz A, Núñez G, García C, Boshell J. Epidemiología molecular de epizootias de rabia en Colombia, 19942002: evidencia de rabia humana y canina asociada con quirópteros. Biomédica. 2003:23:19-30.

32. Brito E, Palacios H, Yunda HR, Martínez J, Reyes L. Construcción de un modelo espacial para determinar áreas de riesgo en Colombia. Rabia de origen silvestre en Colombia. ICA 2005. Fecha de consulta: 17 de noviembre de 2008]. Disponible en: www.ica. gov.co/getattachment/9a95b63a-fc49-435d-8013d6b7aeaf506b/Publicacion-8.aspx.

33. Ferraz C, Achkar SM, Kotait I. First report of rabies in vampire bats (Desmodus rotundus) in an urban area, Ubatuba, Sao Paulo State, Brazil. Rev Inst Med Trop Sao Paulo. 2007;49:389-90.

34. Hemachudha T, Phuapradit P. Rabies. Curr Opin Neurol. 1997;10:260-7.

35. Hemachudha T, Phanuphak P, Sriwanthana B, Manutsathit S, Siriprasomsup W, Ukachoke C, et al. Immunologic study of human encephalitic and paralytic rabies: preliminary report of 16 patients. Am J Med.1988;84:673-7. 
36. Hemachudha T, Tirawatnpong S, Phanthumchinda K. Seizures as the initial manifestation of paralytic rabies. $J$ Neurol Neurosurg Psychiatry. 1989;52:808-10.

37. Dürr S, Naïssengar S, Mindekem R, Diguimbye C, Niezgoda M, Kumin I, et al. Rabies diagnosis for developing countries. PLoS Negl Trop Dis. 2008;2:e206. doi:10.1371/journal.pntd.0000206. Fecha de consulta: 24 de junio de 2008]. Disponible en: http://www. plosntds.org/article/info\%3Adoi\%2F10.1371\%2Fjournal. pntd.0000206

38. Hemachudha H. Rabies. En: Vinken PJ, Bruyn GW, Klawans HL, editors. Handbook of clinical neurology. Viral Disease. Vol 56. Amstderdam: Elsevier Science Publishers; 1989. p. 383-404.

39. Awasthi M, Parmar H, Patankar T, Castillo M. Imaging findings in rabies encephalitis. Am $\mathrm{J}$ Neuroradiol. $2001 ; 22: 677-80$

40. Rumboldt Z. Imaging of topographic viral CNS infections. Neuroimag Clin North Am. 2008;18:85-92.

41. Willoughby RE, Tieves KS, Hoffman GM, Ghanayem NS, Amlie-Lefond CM, Schwabe MJ, et al. Survival after treatment of rabies with induction of coma. N Engl J Med. 2005;352:2508-14.
42. Jackson AC. Rabies virus infection: An update. J Neurovirol. 2003;9:253-8.

43. Lockhart BP, Tordo N, Tsiang $\mathbf{H}$. Inhibition or rabies virus transcription in rat cortical neurons with the dissociative anesthetic ketamine. Antimicrob Agents Chemother.1992;36:1750-5.

44. Reich DL, Silvay G. Ketamine: an update on the first twenty-five years of clinical experience. Can $J$ Anaesth.1989;2:186-97.

45. Leestma JE. Viral infections of the nervous system. En: Davis R, Robertson D, editors. Textbook of neuropathology. Baltimore: Williams Wilkins; 1981. p. 804-903.

46. Nuovo GJ, DeFaria DL, Chanona-Vilchi JG, Shang Y. Molecular detection of rabies encephalitis and correlation with cytokine expression. Mod Pathol. 2005;18:62-7.

47. Instituto Nacional de Salud. Sistema de Vigilancia en Salud Pública- SIVIGILA. Semana 38. Fecha de consulta: 17 de noviembre de 2008]. Disponible en: http://www. ins.gov.co/pdf/vcsp/Tablas/2008/2008_Semana 38.pdf 